15 Arneil GC, MacLaurin JC. Case of adder bite with thrombosis of the saphenous vein. BMF 1961;i:1587-8. 16 Marquart H. Recherches statistiques sur les accidents par Marquart $\mathrm{H}$. Recherches statistiques sur les accidents par
morsures de serpents au Danemark et en Suède de 1900 à morsures de serpents au Danemark

7 Reid HA. Adder bites in Britain. BMF 1976;ii:153-6.

18 Moran CJ. Vipers and viper bites in the West Country. Bristol Med Chir ₹ 1970;85:3-6.

19 Morton TC. Adder bites in Cornwall. BMF 1960;ii:373-6. 20 Prestt I. An ecological study of the viper Vipera berus in southern Britain. F Zool Lond 1971;164:373-418.

21 Birch CA. Snake bite in Britain. Practitioner 1959;183:1058.

22 Borresen HC, Carlsen KH. Zagreb antiserum against envenomation by the adder, Vipera berus. Tidsskr Nor Laegeforen 1979;99:588-90.

23 Cederholm I, Lennmarken C. Vipera berus bites in children-experience of early antivenom treatment. Acta Paediatr Scand 1987;76:682-4.

24 Scheimenz $\mathrm{H}$, Biella $\mathrm{HJ}$. Accidents by stings of the common viper (Vipera b. berus L.) in the years 1955 to 1975 in viper (Vipera b. berus L.) in the years
Saxony. Zool-Abh (Dres) 1978;34:229-43

25 Hemmes GD. Viper bites in The Netherlands. Lacerta 1975;33:55-62.
26 Weatherall DJ, Ledingham JGG, Warrell DA (eds). Oxford textbook of medicine, 3rd ed. Oxford: Oxford University Press, 1996.

27 British national formulary. London: British Medical Association and Royal Pharmaceutical Society of Great Britain ation and Royal

28 Kaufmann C. Faelle von Schlangenbissen, die in der Schweiz beim Menschen zur Beobachtung gekommen sind. Corres-B1 Schweiz Aerzte 1892;22:689-96.

29 Børresen HC, Wagner K. Adder bites, lung injury and delayed infusion of Zagreb antivenom. Tidsskr Nor Laegeforen 1982;102:840-2

30 Warrell DA. In: Thorpe RS, Wuster W, Malhotra A, eds. Venomous snakes: ecology, evolution and snakebite. Symposium of the Zoological Society (London). Oxford: Oxford University Press (in press).

31 Williams V, White J. In: Thorpe RS, Wuster W, Malhotra A, eds. Venomous snakes: ecology, evolution and snakebite. Symposium of the Zoological Society (London). Oxford: Oxford University Press (in press)

32 Theakston RDG. In: Thorpe RS, Wuster W, Malhotra A eds. Venomous snakes: ecology, evolution and snakebite. eds. Venomous snakes: ecology, evolution and snakebite. Oxford University Press (in press)

\title{
Septic and non-septic olecranon bursitis in the accident and emergency department-an approach to management
}

\author{
Accident and \\ Emergency \\ Department, Guy's \\ Hospital, St Thomas \\ Street, London SE1 \\ 9RT, United Kingdom \\ I M Stell \\ Correspondence to: \\ Dr I M Stell. \\ Key terms; bursitis \\ olecranon bursitis; \\ Staphylococcus aureus \\ NSAIDs \\ Accepted for publication \\ 15 May 1996
}

Olecranon bursitis is a relatively common problem presenting to accident and emergency (A\&E) departments. One third of cases are likely to be septic. The remainder are referred to in this paper as non-septic olecranon bursitis, which includes the cases sometimes termed traumatic or idiopathic olecranon bursitis. Occasional cases are related to rheumatoid arthritis or gout. As the clinical diagnosis can be difficult, septic cases are often not diagnosed; treatment with anti-inflammatory agents alone then leads to a delay in diagnosis and worsening suppuration. Incision and drainage can often be avoided by initial aspiration and antibiotics.

In this paper I discuss the aetiology of these conditions, the various tests which can identify the septic cases, the treatment options, and finally suggest an approach to management in A\&E.

\section{Epidemiology}

The overall incidence of olecranon bursitis is not known. The vast majority of cases are seen in males, typically aged $30-60$ years.

\section{Aetiology}

In non-septic olecranon bursitis, inflammation arises either because of bleeding into the bursa, or through the release of inflammatory mediators following trauma. ${ }^{12}$ This inflammation can lead to permanent damage to the epithelial lining of the bursa, predisposing to repeated attacks in the future.

In septic olecranon bursitis, trauma, breaks in the skin, or foci of infection provide a portal of entry from which bacteria appear to migrate across soft tissues to enter the bursa. ${ }^{34}$ However, there is not always a good history of trauma, so penetration through minute breaks in the skin must occasionally happen. Haematogenous spread does not appear to be the usual route of infection. ${ }^{5}$ Ninety per cent of aspirates cultured reveal Staphylococcus aureus, and most of the remainder are infected with $\beta$ haemolytic streptococci. ${ }^{6-8} \mathrm{~A}$ range of more unusual organisms-Gram positive and Gram negative bacteria, mycobacteria, and fungihave been identified in infected olecranon bursae, frequently in the context of systemic diseases. There is evidence that many of these are spread by the haematogenous route. ${ }^{5}$

About one third of septic olecranon bursitis cases have a history of a previous episode of olecranon bursitis. It may be that in these cases the fibrosis and distortion of vascular architecture from previous inflammation prevents the bursa from dealing efficiently with foreign material, such as bacteria. ${ }^{2}$ The olecranon bursa has a relatively poor blood supply, which is in contrast to the synovial membranes of joints. ${ }^{9}$ This may, in part, explain why septic olecranon bursitis is much commoner than septic arthritis. The bursal membrane is biologically different from that of joints. ${ }^{410}$

Impaired immunity is an important aetiological factor in up to half of all septic cases. The most common reason is alcohol abuse, but steroids, diabetes, renal impairment, and malignancy are also responsible. ${ }^{11}$

\section{Presenting features}

The onset of symptoms can be over several hours or several days. The degree of inflamma- 
tion can range from a painless inconvenient lump to a painful hot swelling with extensive cellulitis, accompanied by a fever.

\section{Diagnosis}

The clinical features may suggest gout or rheumatoid arthritis as the cause, and may help to differentiate septic from non-septic olecranon bursitis. Patients with septic olecranon bursitis usually seek help earlier, and about half are febrile. ${ }^{6}$ Bursae which are simply swollen with no pain are almost always non-septic. ${ }^{2}$ Pain, warmth, and tenderness, although worse in septic cases, are poor discriminators. Erythema, although seen in $63-100 \%$ of septic cases, is also seen in $25 \%$ of non-septic cases. ${ }^{6}$ On aspiration, purulent fluid indicates septic olecranon bursitis, but a serosanguinous or hazy appearance is often seen in both conditions.

Laboratory tests are essential to differentiate septic from non-septic bursitis when doubt remains after clinical examination, so the aspirate should be sent for microscopy and culture. Microscopy may identify urate crystals, as rarely the first presentation of gout can be with olecranon bursitis. ${ }^{10}$ Gram stain shows the presence of bacteria in $53-100 \%$ of septic cases. ${ }^{67}$ Bacterial culture identifies a causative organism in practically all cases of septic bursitis that have not already received antibiotics. ${ }^{311}$

Total and differential white cell counts in the bursal fluid are rapid, sensitive, and specific tests for identifying septic cases. Although these tests are not offered routinely, many laboratories are able to perform them. The total white cell count is usually greater than $100 \times 10^{9} /$ litre (range 1-300) in septic cases, and less than $5 \times 10^{9} /$ litre (range 0.05-11) in nonseptic cases. ${ }^{36}$ Neutrophils average $85 \%$ (range $52-98 \%$ ) in septic cases and $29 \%$ (range $0-90 \%)$ in non-septic cases. ${ }^{26}$ These tests can be performed with anticoagulated samples and the automated cell counters used in haematology. The commonly performed semiquantitative methods of reporting cells in wet preparations will usually report large numbers of cells in both septic and non-septic olecranon bursitis, and will not be able to differentiate between these two conditions.

Serum/bursal fluid glucose concentration differences are more marked in septic cases, but this has poor sensitivity as a diagnostic test. $^{56}$

If there is any doubt about the diagnosis then treatment should be given as for a septic case until culture results are available.

\section{Treatment}

Antibiotic treatment alone will not prevent progression of many cases of septic olecranon bursitis, so initial aspiration to dryness is recommended. ${ }^{45}$ This should be repeated as fluid reaccumulates. If the fluid is viscous or particulate, then lavage with sterile normal saline through a large needle will improve drainage. ${ }^{5}$ Incision and drainage may be necessary if there is a pointing abscess, or aspiration and antibiotics fail to control sepsis. ${ }^{5}$ In some severe cases, placement of an intrabursal cath- eter followed by continuous irrigation with an antibiotic solution has been advocated as an alternative. However patients treated in this way have required lengthy admissions. ${ }^{12}$ In refractory cases, particularly those with a chronic discharging sinus, or in recurrent cases, bursectomy may be necessary. ${ }^{6}$

Penicillins and erythromycin appear to penetrate the olecranon bursa well, reaching concentrations comparable to those in serum. Concentrations of oxacillin (related to flucloxacillin) greater than 10 times the minimum inhibitory concentration for $S$ aureus can be achieved with standard oral doses. Much higher levels can been achieved with parenteral treatment. ${ }^{6}$ Standard doses are effective in sterilising the bursa in a mean of five days in immunocompetent patients, but tend to take much longer in those cases which begin treatment late. Similarly the time to sterilisation is longer, with an average of about 11 days in those with impaired immunity. ${ }^{611}$ Patients with systemic sepsis should have parenteral treatment. ${ }^{5}$ Olecranon bursitis caused by any of the more unusual organisms will have to be managed along with any underlying disease, and antibiotic treatment should be guided by bacterial sensitivities.

If non-septic olecranon bursitis is treated by aspiration alone, then half the cases will settle in two weeks, but a quarter will still have a bursal effusion at eight weeks, and $10 \%$ at six months. ${ }^{13}$ It is likely that the addition of non-steroidal anti-inflammatory drugs (NSAID) should lead to a more rapid resolution of symptoms, but the only controlled trial to compare these two options failed to prove this, perhaps because of the small size $(n=42)$ of the study, with patients randomised to one of four treatment options. This study did, however, show that intrabursal methylprednisolone led to a markedly more rapid reduction in bursal swelling than either aspiration alone or aspiration and NSAID, and there were also less recurrent cases over six months of follow up. ${ }^{14}$ Concern has been raised that intrabursal steroids may cause long term problems, including skin atrophy, chronic local pain, and local infection. ${ }^{13}$ This trial did not find evidence of long term problems, but because of its small size and short period of follow up (maximum six months), this concern still remains.

\section{Prognosis}

With aspiration and adequate antibiotic treatment from early in the natural course, septic olecranon bursitis will usually resolve completely without the need for surgical drainage. However, symptoms may still be prolonged, with a mean of five weeks to complete resolution, and occasional cases may take five or more months. ${ }^{15}$ Persistent sinuses may follow incision ${ }^{15}$ or spontaneous rupture, and may necessitate bursectomy.

In non-septic olecranon bursitis effusion may persist for weeks, but pain usually settles more rapidly.

Recurrent episodes of non-septic bursitis may occur after either septic or non-septic bur- 
sitis, and are particularly common where there are repeated episodes of minor trauma.

\section{Suggested approach to management in A\&E}

(1) Rheumatoid arthritis and gout need to be considered as causes.

(2) All cases of olecranon bursitis should be aspirated, whether inflamed or not.

(3) Microscopy for cells and crystals, Gram stain, and culture should be requested. In cases where the bursa is clinically inflamed antibiotics should be given until the culture results are available, when a firm diagnosis of septic or non-septic olecranon bursitis can be made. Cases which are clearly non-septic can be treated with NSAID if there are no contraindications.

(4) All cases should be reviewed after two or three days to confirm the diagnosis, check on progress, and assess the need for further aspiration.

(5) Flucloxacillin should be the antibiotic of choice while culture results are awaited. Penicillin should be added in more severe cases, or the appropriate antibiotics for any of the more unusual organisms. The patient should be admitted for parenteral antibiotics if there is extensive cellulitis or a pyrexia. Antibiotics should be continued for 10 days at least. The course may need to be longer in immunosuppressed cases, and will be guided by response, and the results of repeat culture of aspirate in some cases. In penicillin-allergic patients erythromycin can be used, although at least two weeks of treatment will be required, as sterilisation of the bursa may take longer because erythromycin is bacteriostatic rather than bacteriocidal.

(6) Surgical management should be considered if there is a pointing abscess, or no improvement on antibiotics.

\section{Summary}

Olecranon bursitis is relatively common. One third of episodes are septic. Most of the remainder are non-septic, with occasional rheumatological causes. Trauma can cause both septic and non-septic olecranon bursitis. Clinical features are helpful in separating septic from non-septic olecranon bursitis, but there may be local erythema in both. Aspiration should be carried out in all cases, and if the presence of infection is still in doubt, microscopy, Gram staining, and culture of the aspirate will resolve the issue. Septic olecranon bursitis should be treated by aspiration, which may need to be repeated, and a long course of antibiotics. Some cases will need admission, and a few will need surgical treatment. Non-septic olecranon bursitis can be managed with aspiration alone. Non-steroidal antiinflammatory drugs probably hasten symptomatic improvement. Intrabursal corticosteroids produce a rapid resolution but concern remains over their long term local effects. Recovery from septic olecranon bursitis can take months.

I am grateful for the advice of Dr I O'Sullivan and Mr D P Watson, of the Accident and Emergency Department, and Prof R Grahame of the Rheumatology Dept, Guy's Hospital.

1 Smith DL, Bakke AC, Campbell SM, Beckstead JH. Immunocytological characteristics of mononuclear cell populations found in nonseptic olecranon bursitis. $\mathcal{F}$ Rheumatol 994;21:209-14.

2 Canoso JJ. Idiopathic or traumatic olecranon bursitis. Clinical features and bursal fluid analysis. Arthritis Rheum 1977; 20:1213-6.

3 Ho G, Tice AD, Kaplan SR. Septic bursitis in the prepatellar and olecranon bursae: an analysis of 25 cases. $A n n$ Intern Med 1978;89:21-7.

4 Ho G, Mikolich DJ. Bacterial infection of the superficial subcutaneous bursae. Clin Rheum Dis 1986;12:437-57.

5 Zimmerman B, Mikolich DJ, Ho G. Septic bursitis. Semin Arthritis Rheum 1995;24:391-410.

$6 \mathrm{Ho}$ G, Tice AD. Comparison of nonseptic and septic bursitis; further observations on the treatment of septic bursitis. Arch Intern Med 1979;139:1269-73.

7 Thompson GR, Manshady BM, Weiss JJ. Septic bursitis. fAMA 1978;240:2280-2.

8 Smith DL, McAfee JH, Lucas LM, Kumar KL, Romney DM. Septic and nonseptic olecranon bursitis. Utility of the surface temperature probe in the early differentiation of septic and nonseptic cases. Arch Intern Med 1989;149: 1581-5

9 Davies DV, Edwards DAW. The blood supply of the synovial membrane and intraarticular structures. Ann $R$ Coll Surg Engl 1948;2:142-56.

10 Canoso JJ, Yood RA. Acute gouty bursitis: report of 15 cases. Ann Rheum Dis 1979;38:326-8.

11 Roschmann RA, Bell CL. Septic bursitis in immunocompromised patients. Am $\mathcal{F}$ Med 1987;83:661-5.

12 Knight JM, Thomas JC, Maurer RC. Treatment of septic olecranon and prepatellar bursitis with percutaneous placement of a suction-irrigation system: a report of 12 cases. Clin Orthop Related Res 1986;206:90-3.

13 Weinstein PS, Canoso JJ, Wohlgethan JR. Long-term follow-up of corticosteroid injection for traumatic olecranon bursitis. Ann Rheum Dis 1984;43:44-6.

14 Smith DL, McAfee JH, Lucas LM, Kumar KL, Romney DM. Treatment of nonseptic olecranon bursitis, a controlDM. Treatment of nonseptic olecranon bursitis, a controlled, blinded

15 Raddatz DA, Hoffman GS, Franck WA. Septic bursitis, presentation, treatment and prognosis. $\mathcal{F}$ Rheumatol 1987; 14:1160-3. 